\title{
La reducción estética del arte
}

\author{
JOSÉ GARCÍA LEAL \\ Universidad de Granada
}

\section{De LO ARTístico A LO ESTÉTICO}

ES EN LA MODERNIDAD CUANDO el arte se piensa como arte y la experiencia estética toma conciencia de serlo. Sin duda, lo artístico y lo estético existían desde mucho antes. Lo que inaugura la modernidad no es tanto un arte nuevo, o la elección de nuevos objetos estéticos, como la nueva conciencia que de sí mismos toman lo artístico y lo estético.

La originalidad de la conciencia moderna descansa ante todo en la autonomía que se atribuye a ambos dominios. La autonomía no quiere decir, como a veces se malinterpreta (o como corresponde a ciertas versiones degradadas de la idea de autonomía), que lo artístico y lo estético queden separados de la vida, que se aíslen en un mundo aparte tras haberse puesto entre paréntesis las exigencias y expectativas de la existencia ordinaria. No quiere decir confinar el arte y la estética a los «domingos de la vida», según la atinada expresión de Hegel. Autonomía significa más bien que tanto lo artístico como lo estético tienen su propia razón de ser, que se justifican en sí y por sí mismos, que no son vicarios de nada, no están al servicio de la moral, la política, la religión o cualquier otra cosa. Sólo se relacionan con lo demás desde la afirmación de una identidad propia.

Pero la autonomía que lo artístico y lo estético reclaman para sí es también una fuente de tensión entre ambos. Como si cada uno de ellos constituyese un polo de atracción que pretende atraer al otro e integrarlo en su propia empresa. Lo artístico y lo estético, en su acepción moderna, nacen en una relación mutua que es a la vez de complementariedad y de conflicto entre ambos.

Se complementan en la medida en que están posibilitados por un mismo contexto histórico y de algún modo cada uno hace referencia al otro, lo incluye en su propio horizonte. Aunque el discurso sobre lo estético (en Kant, especialmente) es lo originario y se aplica inicialmente a la belleza natural, configurándose en torno a ella las características fundamentales del juicio estético, no puede dejar de ocuparse en un segundo momento del arte y la belleza artística. 
Por más que resulte problemático el encaje del arte en unos parámetros definidos por la mera representación de la forma bella, la belleza no sustentada en concepto alguno. De otro lado, cuando la reflexión sobre el arte se hizo prioritaria (a partir de Hegel) y el arte se define sólo por él mismo, no pudo dejar de lado la dimensión estética del arte, pues se trataba en definitiva de las «bellas artes», las que daban una encarnación sensible, estética, a la idea.

La relación de complementariedad, decíamos, fue también desde el principio una relación conflictiva. Un conflicto que no ha dejado de acentuarse con el paso del tiempo y que se ha exacerbado desde la aparición de las vanguardias a comienzos del siglo XX, llegando a su expresión final en las neovanguardias de las últimas décadas. No quiere decirse que el conflicto se haya dado en todas las corrientes y periodos artísticos; no se pretende absolutizarlo. Pero es innegable que constituye una tendencia muy relevante en el devenir moderno de las artes. Ha conducido al divorcio frecuente de lo artístico y lo estético, y en ocasiones a su contraposición excluyente o a la asimilación reductora de lo uno a otro.

De hacer caso a Heidegger, desde el inicio la modernidad incuba en su seno la reducción de lo artístico a lo estético (si es que la entrevió, le debió parecer irrelevante la tendencia contraria, la de un arte que niega belicosamente cualquier ingrediente estético). Para él, uno de los fenómenos esenciales de la época moderna es «el proceso que introduce al arte en el horizonte de la estética. Esto significa que la obra de arte se convierte en objeto de la vivencia y, en consecuencia, el arte pasa por ser expresión de la vida del hombre» ${ }^{1}$. La introducción del arte en el horizonte de la estética comporta una doble reducción: la belleza queda reducida al sentimiento de gusto -el gusto como mera expresión de la vivencia subjetiva-, y el arte se reduce a belleza. El proceso se inicia con la relativización de la belleza y su supeditación al sentimiento: es bello lo que gusta, o sea, lo que lo que al mostrase y ser percibido produce placer, lo que refuerza y favorece «el sentimiento de la vida», en palabras de Kant. Y a partir de ahí se abren las puertas a la idea del arte como mero portador o sustento de belleza, un arte sin más contenido ni valor que la belleza que ofrece. Así, el arte mismo queda supeditado al sentimiento, a las determinaciones del gusto: su única función es el deleite estético.

Podrá dudarse de que el diagnóstico de Heidegger sea acertado en conjunto, por reducir lo plural y diverso de las prácticas artísticas a algo único y homogéneo, por absolutizar una tendencia que no es sino una más de las muchas que agitan el arte contemporáneo. Pero aun en su parcialidad, no puede excluirse que la reducción del arte a lo estético sea uno de los fenómenos característicos

1 M. Heidegger, «La época de la imagen del mundo», Caminos del bosque, tr. H. Cortés y A. Leyte. Madrid: Alianza Editorial, 1995, pp. 75-76. 
de la historia próxima y de la situación actual del arte. A él se consagran exclusivamente las páginas que siguen.

\section{LO ESTÉTICO, EN LA TEORÍA Y EN LOS HECHOS}

A riesgo de insistir en lo ya sabido, conviene precisar algo él significado del término «estético» para fijar en lo posible el alcance de la reducción estética. En su acepción más simple, entendemos por estético todo lo relacionado con $l a$ contemplación hedonista de la belleza. Para señalar sus connotaciones teóricas hay que referirse al período fundacional de la Estética, la nueva disciplina que va tomando cuerpo y busca legitimar su autonomía a lo largo del siglo XVIII. El objeto de la Estética, en la formulación inicial de Baumgarten, es el estudio de la cognitio sensitiva, esa forma específica de conocimiento que se diferencia tanto de la impresión sensible como del conocimiento intelectivo, que no es reductible a conceptos ni sensaciones. Trata de justificar teóricamente un modo especial en la que la conciencia se representa las cosas: el modo en el que ciertas cosas se ofrecen a la conciencia, se dan a conocer y, por su parte, la conciencia las toma como objetos. Tal es el conocimiento sensible, o como acaso se diría hoy, la percepción sensible; y no cualquier percepción, sino la percepción sensible de la belleza. La Estética trata, pues, de la percepción sensible de la belleza, o mejor, de la percepción y el juicio estéticos.

La primera exigencia a la que se enfrentó fue la de caracterizar lo que hay de específico en la percepción estética, el modo peculiar en que se representa las cosas y que la distingue de otros tipos de percepción. La noción kantiana de desinterés resultó ser la más decisiva para determinar lo específico de la percepción, y de ahí que el desinterés haya estado casi siempre asociado a la percepción estética. Así, la percepción es estética cuando se desinteresa de la dimensión teórica, moral y utilitaria de sus objetos, cuando pone entre paréntesis toda utilidad práctica. Eso, según Kant, le hace ser contemplativa: queda concentrada en la presencia sensible del objeto, desinteresándose de las condiciones reales de existencia de ese objeto. En otra terminología, la percepción estética es intransitiva: no ve nada a través y más allá del objeto, ninguna utilidad, función o relación en que incluirlo; queda detenida en él y en él se refleja.

Por otro lado, la idea de percepción estética toma cuerpo teórico en el seno de una cultura que ha entronizado la subjetividad como principio explicativo, centro desde el que irradia todo sentido. Es lógico que la impronta subjetiva marque también a la percepción. El subjetivismo impregna por igual al ejercicio de la percepción, o actividad perceptiva, y al objeto percibido. La acción perceptiva se explica desde las condiciones trascendentales de la subjetividad o desde la sensibilidad y el hábito subjetivos, pero remitiendo siempre a las 
determinaciones del sujeto que percibe, a sus disposiciones y aptitudes.

A su vez, aquello que se percibe tiene igualmente una determinación subjetiva. La percepción estética es percepción de lo sensible: lo que percibe la percepción es lo sensible. Pero no lo sensible sin más, sino lo sensible bello, lo sensible en la plenitud o excelencia de su manifestación, pues no otra cosa es inicialmente la belleza sino el esplendor de lo sensible ${ }^{2}$. Ahora bien, la belleza no es una cualidad en sí del objeto, al margen de la relación que entablamos con él. La belleza es relativa: su determinación última no la da el objeto, sino la relación de éste con un sentimiento subjetivo, el sentimiento de placer. Es bello lo que produce placer. Y el sentimiento placentero es lo que se expresa en el juicio del gusto. El gusto es la razón última de la percepción. O en otras palabras, el gusto se convierte en el auténtico eje de la percepción estética. El juicio estético es un juicio de gusto.

El gusto conlleva de por sí un elemento valorativo. La percepción estética tiene, pues, dos vertientes, correlativas e inseparables. Por un lado es contemplación, visión del objeto. Por el otro es apreciación o evaluación. Al ver el objeto lo valoro, lo juzgo bello o feo en la medida en que me gusta o disgusta.

Puede decirse que lo anterior es lo básico, lo que incluye de más genérico la noción de juicio estético trasmitida por la Estética fundacional. A partir de aquí caben distintas preguntas y diversos enfoques para afrontarlas. Una de las cuestiones fundamentales es la de la relación entre el juicio de gusto y las propiedades del objeto sobre el que recae el juicio. Y de ahí una alternativa: puede pensarse que el gusto es enteramente subjetivo, depende únicamente de las disposiciones, aptitudes, formación, hábitos, etc. del sujeto que lo emite, o bien, tiene alguna relación con las cualidades del objeto que gusta.

Desde una perspectiva, las cosas bellas son las que gustan al sujeto, y son bellas exclusivamente porque le gustan. El gusto subjetivo es lo único que articula la acción perceptiva y lo percibido: la actividad perceptora y el objeto (bello) percibido coinciden y se armonizan porque ambos responden a la misma determinación subjetiva. O mejor, lo bello es bello porque concuerda con la disposición subjetiva.

Desde la otra perspectiva, la subjetividad del gusto no excluye la observación e identificación de ciertas cualidades de los objetos que condicionan el gusto, a las que el gusto responde. No hay belleza si un sujeto no la contempla y reconoce como tal; en ese sentido cabe entender la afirmación de Hume de que

2 L. Ferry, en Homo Aestheticus. L'invention du goüt à l'âge dèmocratique, París: Bernard Grasset, 1990, pp. 33-ss., ha analizado como una de las cuestiones fundamentales de la Estética la reivindicación de la autonomía de lo sensible, una vez desgajado de la divinidad. Lo sensible pierde el sello de la imperfección y se abre a la invención de un mundo del que se ha retirado lo divino. 
«la belleza existe sólo en la mente que la contempla ${ }^{3}$. Pero ello no obsta a que el gusto esté influido por las cualidades propias del objeto. Como dice después Hume, «aunque es verdad que la belleza y la deformidad no son cualidades de los objetos más de lo que puedan serlo lo dulce y lo amargo, sino que pertenecen enteramente al sentimiento, interno o externo, debe admitirse que hay ciertas cualidades en los objetos que por naturaleza son apropiadas para producir estos sentimientos particulares» ${ }^{4}$. Por eso es posible y conveniente discutir sobre los gustos, por eso unos gustos son mejores que otros. Son mejores los que mejor disciernen las cualidades del objeto. De ahí la conveniencia de educar el gusto, de dotarlo de esa delicadeza que es propia del buen gusto.

Aunque habría que justificarlo, creo que con esa doble perspectiva está relacionada la respuesta a otra cuestión. ¿A través del conocimiento, la deliberación, el refinamiento de mis capacidades perceptivas, la educación del gusto, puedo cambiar mi valoración, incluso mi visión del mismo objeto? ¿Al ver un objeto con ojos nuevos y más penetrantes, al discernir mejor sus cualidades, puede cambiar mi valoración del objeto?

Quienes crean que las propiedades del objeto afectan al gusto y, sobre todo, crean que la delicadeza del gusto te permite ver ciertas cualidades del objeto que de otro modo no verías, probablemente piensen que un conocimiento mejor del objeto puede hacer que varíe tu juicio estético. Si no en la apreciación presente, si en otra próxima en la que vuelvas a contemplarlo, tras conocerlo mejor. Desde un punto de vista alternativo, supuestamente más fiel a Kant, otros pensarán que no es así. Por citar un ejemplo significativo, Clement Greenberg mantiene que «el juicio estético es no voluntario [...] Tu juicio estético, al ser una intuición y nada más, es recibido, no ejercido. No escoges que te guste o disguste cierto ejemplar de arte del mismo modo que no escoges ver que el sol es brillante o la noche es obscura [...] La evaluación estética es refleja, automática, inmediata, no llega en lo más mínimo a través de la voluntad, la deliberación o el razonamiento» ${ }^{5}$. En otras palabras, si algo te gusta o disgusta, eso no lo cambia ningún análisis o instrucción sobre las cualidades del objeto.

Dejamos sin desarrollar estas cuestiones, sin duda más complejas de lo que aquí se ha esbozado. La mención de los rasgos fundamentales de lo estético debía servirnos para aclarar el significado de la reducción estética del arte. Significa, por todo lo anterior, que el arte queda limitado a lo estético, deviene objeto de

3 D. Hume, «La norma del gusto», tr. M. T. Begiristain, Valencia: Revista Teorema, 1980, p. 8.

4 Ibid., p. 9. Sobre este particular puede verse el libro de Y. Michaud, El juicio estético, tr. G. Vilar, Barcelona: Idea Books, 2002.

$5 \mathrm{Cl}$. Greenberg, Homemade Esthetics. Observations on Art and Taste, Oxford and New York: Oxford University Press, 1999, p. 7. 
una percepción que lo asimila a lo estético, que sólo ve en el arte lo que en él pueda haber de estético. El arte es el correlato de una contemplación desinteresada e intransitiva para la que sólo cuenta lo sensible, la forma bella. Una belleza, a la vez, que viene determinada por el sentimiento subjetivo de placer, el gusto. Asimilado a la belleza, el arte queda reducido a objeto del gusto.

La reducción puede darse tanto en la teoría como en los hechos. Antes de pasar a la teoría, dirigimos una breve mirada a los hechos. Y nos situamos ya para lo uno y para lo otro en la inmediatez de nuestro presente.

Algunos autores han coincidido en diagnosticar como lo más característico de nuestros días la desaparición del arte (o al menos, de las obras de arte tradicionales) que se corresponde con el triunfo generalizado de lo estético. Así, Baudrillard afirma: «Hoy el arte está realizado en todas partes. Está en los museos, está en las galerías, pero está también en la banalidad de los objetos cotidianos; está en las paredes, está en la calle, como es bien sabido; está en la banalidad hoy sacralizada y estetizada de todas las cosas, aún los detritos, sobre todo los detritos. La estetización del mundo es total» ${ }^{6}$. Quiere decirse que todo está sometido a la estética, desde los objetos cotidianos hasta las obras de arte tradicionales, las depositadas en los museos, pasando por los objetos, instalaciones, acciones, intervenciones, dispositivos varios que han sustituido a las obras clásicas. Están sometidos a la estética en tanto sólo merecen una recepción estética, sólo se los contempla desde los parámetros del gusto. El objeto artístico, genuino o sucedáneo, se ha convertido en mera «prótesis estética».

Benjamin contraponía la recepción basada en el recogimiento, que merece la obra aurática, a la recepción caracterizada por la distracción que corresponde a las obras sometidas a la reproducción técnica. El recogimiento sumerge el espectador en la obra, hace que se adentre ella, que la contemple en una actitud de escucha o apertura receptiva; la distracción disipa y dispersa la atención, de forma que la obra queda a disposición del espectador: el espectador no se sumerge en la obra sino que sumerge en sí a la obra. Benjamin aún encontraba elementos positivos en esta última forma de recepción; en todo caso, era la que convenía a las nuevas formas artísticas. Lo que apunta Baudrillard tiene connotaciones distintas. Cuando todo está estetizado, hasta la propia experiencia estética se disuelve en la trivialidad. La estética se desborda y en su expansión ilimitada pierde su especificidad, su razón de ser y objetivos propios. «Mientras más valores estéticos hay en el mercado menos posibilidades hay, en cierta manera, de un juicio estético, de un placer estético» 7 .

6 J. Baudrillard, La ilusión y la desilusión estéticas, tr. J. Fombona, Caracas: Monte Avila, 1998, p. 49.

7 Ibid., p. 48. 
Ha sido Yves Michaud quien ha llevado más lejos el diagnóstico de la estetización generalizada. Mantiene que la belleza se ha impuesto por doquier, que todo requiere de la belleza para ser comunicable, consumible, comercializable. Es el triunfo de la estética. Pero lo que gana la estética lo pierde el arte. «La paradoja que me va a ocupar es que la belleza y, con ella, un tal triunfo de la estética se cultivan, se difunden, se consumen y se celebran en un mundo vacío de obras de arte, si entendemos por tal esos objetos preciosos y raros que antes estaban investidos de un aura, de una aureola, de la cualidad mágica de ser focos de producción de experiencias estéticas únicas, elevadas y refinadas. Es como si, al haber más belleza, hubiera menos obras de arte, y más lo artístico se expande y colorea todo, pasando por así decir al estado de gas o de vapor y recubriendo todas las cosas como con un vaho. El arte se ha volatizado en éter estético, si se recuerda que el éter fue concebido por los físicos y filósofos después de Newton como ese medio sutil que impregna todo los cuerpos» ${ }^{8}$. Es una situación compleja, que engloba diversos rasgos y responde a distintos procesos. Sin seguir en su totalidad el análisis de Michaud, destacamos algunos aspectos que nos parecen especialmente relevantes.

Una de las tendencias que conducen al triunfo de la estética, señala Michaud, es la que promueve la desaparición de la obra artística como objeto acabado, arraigado en la materialidad sensible y con una configuración definida. En su lugar aparecen dispositivos, procedimientos, entornos calculados para producir una cierta gama de efectos, para generar determinadas experiencias. Por más que perduren algunas obras de arte tradicionales, la idiosincrasia del arte último privilegia el efecto en lugar de la obra; todo le sirve con tal que genere cierta experiencia, que afecte a alguien, le emocione, sorprenda, conmueva, divierta o repugne. Lo que hace artístico a cualquier artilugio o actuación es sólo el servir de resorte para alguna experiencia de tinte estético. El arte no es tanto la obra como el efecto o experiencia producidos.

Algo no muy distinto es lo que Mario Perniola califica como el «vitalismo comunicativo» del arte actual. «Lo que importa es la manifestación de un relacionismo vitalista que puede ser puramente lúdico y gratuito o encaminado, más bien, a adquirir un valor no en el mercado del arte, sino en el de la comunicación [...] Como si la actividad del artista no consistiese tanto en la producción de obras como en la acción, es decir, en una comunicación no subordinada al logro de un cierto fin político, comercial o de cualquier otra índole, y al margen de cualquier otra función que no fuera la de llegar y, eventualmente, comprometer al público»9${ }^{9}$.

No se trata de reivindicar como arte genuino sólo el de las obras clásicas, la pintura, escultura o sinfonía tradicionales. El pluralismo radical de nuestros días

8 Y. Michaud, L'art à l'état gazeux, Paris: Hachette, 2003, p. 9.

9 M. Perniola, El arte y su sombra, tr. M. Poole, Madrid: Cátedra, 2002, p. 10. 
es probablemente irreversible: no hay ya razones para preferir a priori ningún tipo de arte a otro, ninguno es expresión más depurada del espíritu de la época, ni más coherente con la tradición, ni promueve más el avance cultural, ni es legitimable por cualquier otro gran relato. El soporte de una obra, sea electrónico, sea el lienzo o el gesto corporal, no la hace más valiosa que otra, ni más o menos artística. Lo único que son mejores o peores son las obras particulares, ya sean videoinstalaciones, performances o pinturas de caballete.

No se trata de intentar recuperar la obra de arte aurática, entronizada en un tiempo y un lugar únicos, abandonada en su aislamiento. Pero si parece que el «vitalismo comunicativo», la comunicación estética que nada comunica, el arte del efecto, la acción meramente efectista, acaban disolviendo la especificidad del arte. El arte, diluido en la comunicación, no se diferencia de cualquier otro testimonio, noticia o mensaje publicitario. No es que sea arte de masas, frente al arte elitista, es que no es nada, o sólo es un nombre con significado exclusivamente encomiástico. Y todo eso en beneficio de una experiencia estética tan vaga e incierta, tan ociosa e indefinida, como el resorte que la provoca. Una experiencia estética que sólo se identifica por la afectada apelación a la belleza. El arte desde siempre ha buscado la comunicación. Pero la cuestión es si hay algo artístico que comunicar o sólo es artística la comunicación. Si la comunicación prolonga el sentido de una obra o no hay más sentido que la pretensión comunicativa. Aunque si no hay nada que comunicar, ¿en qué consiste la comunicación?

Michaud por su parte también relaciona el triunfo de la estética con la indefinición del arte. Señala que el hecho aceptado de que «no importa qué» pueda convertirse en una obra de arte tiene como consecuencia que lo que hace a algo ser una obra de arte es sólo el procedimiento que la instaura como tal. Ha triunfado una consideración puramente procedimental del arte. Todo el mundo puede hacer arte siempre que se atenga a los procedimientos regulados por el mundo del arte; hace arte el crítico, el agente comercial, el artista y el espectador; el arte está al alcance de todos. Pero lo importante es el cambio radical que todo ello comporta. «La posibilidad de que todo y no importa qué sea arte es precisamente también la posibilidad del triunfo de la estética. Si todo puede ser arte con tal de que se sigan procedimientos de hacer arte que a fin de cuentas son convencionales, entonces todo puede ser visto estéticamente y el arte puede derramarse libremente fuera del mundo del arte, algo cuya defensa ansiosa y obsesiva resulta tan indispensable como platónica y condenada al fracaso. Si los ready-mades están por todos lados, basta con encontrarlos y verlos en todos los sitios donde están» ${ }^{10}$. Si el arte no se caracteriza por nada propio, sin tanto él como sus efectos son inespecíficos, si su única resonancia

10 Y. Michaud, op. cit., p. 54. 
es lo estético, entonces todo puede ser arte, pues todo puede ser objeto de una atención estética, de una contemplación evaluativa, sea de aceptación o de rechazo. A menos arte, más estética.

En el mismo tono que otra cautela anterior, no pretendemos decir que ésta sea una disposición única y unívoca, que la situación actual del arte se reduzca a esto. Sólo que es una tendencia entre otras de las que se disputan la compleja realidad del arte contemporáneo.

\section{LAS DEFINICIONES ESTÉTICAS DEL ARTE}

Nos interesa analizar ahora la relación que pueda haber entre los hechos parcialmente descritos y ciertas definiciones teóricas del arte, en particular las llamadas definiciones estéticas.

Se han dado distintas variantes dentro de la definición estética. No todas comparten los mismos rasgos; antes bien, ponen énfasis en diferentes aspectos y conducen a resultados desiguales, por más que coincidan en la asimilación del arte a lo estético. Vamos a escoger tres versiones de la definición estética que nos parecen especialmente significativas.

A) La primera es la que llamaremos definición formalista. Está representada originaria y ejemplarmente por Monroe C. Beardsley. La formula así: «Una obra de arte es $o$ una combinación de condiciones procurada para ser capaz de permitir una experiencia con marcado carácter estético $o$ (incidentalmente) una combinación perteneciente a la clase o tipo de combinaciones que típicamente se destina a tener esa capacidad» ${ }^{11}$. O más sencillamente: «Una obra de arte es algo producido con la intención de dotarle de la capacidad de satisfacer el interés estético» ${ }^{12}$. Aquí se enuncia el principio básico que comparten todas las definiciones estéticas: lo que hace de algo una obra de arte es su capacidad de provocar una experiencia estética. El acento se desplaza así desde la obra al efecto que provoca. Desde la obra a su recepción por el espectador, al modo en que la obra le afecta. El foco de la definición no se centra en lo que haya de ser la obra de por sí, sino en la experiencia que procura. No en su constitución interna, sino en su función, la función que cumple o puede cumplir.

$¿$ Quiere esto decir que cualquier cosa, sea lo que fuere, puede ser una obra artística con tal de provocar una experiencia estética? ¿Todo puede ser arte por el mero hecho de que alguien lo perciba estéticamente, que en el último extremo

11 M. Beardsley, «Redefining Art», en: M. Wreen y D. Callen (eds.), The Aesthetic Point of View, Ithaca: Cornell University Press, 1982, p. 298.

12 «An Aesthetic Definition of Art», en: H. Cutler (ed.), What is Art?, New York: Haven Publishers, 1983, p. 46. 
podría reducirse a que le guste o disguste? De ser así lo artístico perdería toda especificidad, quedaría reducido a nada. Pues, por un lado, en nuestra sociedad ha triunfado la belleza en el sentido que manifestaba Michaud y todas las mercancías están revestidas de lo estético, el ornato se extiende por doquier, y, por otro lado, incluso lo que carece de todo aspecto estético puede ser objeto de gusto o disgusto. Continuamente nos gustan o disgustan cosas que nada tienen que ver con el arte.

Las definiciones estéticas divergen ante esa cuestión. Creo que la respuesta depende de si atribuyen o no al objeto algunas cualidades internas que lo capacitan para generar la experiencia estética. Cualidades necesarias, pues si las tiene podrá provocar la experiencia, si no, no. Si no se suponen ciertas cualidades internas, no se ve como puede evitarse la conclusión de que la condición artística depende exclusivamente de que alguien contemple cualquier objeto estéticamente. Más aún si, como sucede en algunos casos, se piensa que la actitud, la atención o la experiencia estéticas son indefinibles, carecen de propiedades específicas.

En el caso de Beardsley no parece que cualquier objeto pueda generar una experiencia estética. Antes bien, el objeto artístico es el que está dispuesto o capacitado para generarla. Esa capacidad es fruto de una intención -la obra artística es un producto intencional, no cualquier cosa-e implica una «combinación de condiciones» procurada con vistas al efecto estético. Bien es cierto que Beardsley ha preferido describir las características de la experiencia estética antes que especificar la combinación de condiciones propias del objeto artístico. Es lógico. En definitiva, el acento, la prioridad lógica, el principio explicativo, están en la experiencia, no en la obra, como corresponde a una definición estética. Cuando después anotemos las características de la experiencia estética, podrá pensarse que de algún modo ellas se corresponden con las condiciones de la obra. Unas son mutuo reflejo de las otras. Y ambas Beardsley parece haberlas deducido de los criterios formales de la belleza.

Noël Carroll ha advertido que las definiciones estéticas del arte suponen la combinación de dos afirmaciones. Por un lado, se establece que nuestros encuentros con las obras de arte están conformados por las experiencias estéticas. Por otro, que la obra de arte es un artefacto diseñado para provocar experiencias estéticas. De ahí resulta que la única propiedad determinante del arte es lo estético, lo formal y sensorial. «Estas dos afirmaciones -que las respuestas estéticas son lo distintivo de nuestras respuestas al arte y que los objetos artísticos pueden definirse en términos de lo estético-, aunque notoriamente independientes, pueden sin embargo conectarse por el punto de vista claro y simple de que lo que sea un objeto puede captarse a través de una consideración de su función. El objeto artístico es algo diseñado para provocar un cierto tipo de respuesta, un cierto tipo de interacción. La interacción canónica con 
el arte implica lo estético (como quiera que sea caracterizado). Así, la obra de arte es un objeto diseñado con la función de engendrar experiencias estéticas, percepciones, actitudes y demás» ${ }^{13}$.

Un primer presupuesto de las teorías estéticas, el más explícito y notorio, es el que define lo artístico por el efecto estético. Tal es el que venimos comentando. Un segundo supuesto, hecho notar por Carroll, es el que considera que nuestra respuesta a las obras de arte es fundamentalmente de carácter estético; que la experiencia del arte es específicamente una experiencia estética, marcada por la belleza y el sentimiento del gusto. El que la respuesta a las obras sea de carácter estético excluye que la comprensión, el juego hermenéutico o la comunicación semántica constituyan ingredientes esenciales de de la experiencia en torno al arte. La reducción del arte a lo estético va de la mano con la reducción de la experiencia a un ejercicio estético en el que se prescinde de la dimensión cognitiva del arte, de todo lo relacionado con la simbolización artística. Un tercer supuesto, que aparece claramente en Beardsley, es el que toma lo estético como principal criterio valorativo para juzgar las obras de arte y nuestra relación con ellas. Así, una obra es valiosa si provoca una experiencia estética; y es más valiosa cuanto mayor sea la experiencia provocada. Si lo estético define tanto el arte como la experiencia que lo acoge, va de suyo que sea también el primordial criterio de valor.

¿Qué características ha de tener una experiencia para ser estética? Beardsley ha vuelto en distintas ocasiones sobre esta cuestión y ha descrito de distinto modo esas características. En su obra magna, Aesthetics: Problems in the Philosophy of Criticism, señaló básicamente las siguientes: atención concentrada, intensidad, unidad, coherencia y completud ${ }^{14}$. En un texto posterior ${ }^{15}$ las reformuló como fijación en el objeto, libertad sentida, afecto distanciado, descubrimiento activo y completud. Algunas de ellas son variaciones sobre la idea de una atención estética específica, casi siempre en la estela kantiana de la contemplación desinteresada e intransitiva. Las otras tienden a precisar la estructura formal en que se integran los distintos elementos de la experiencia, estímulos, afectos, emociones, disposiciones anímicas... No son tales o cuales estímulos y sentimientos los que hacen estética a la experiencia, sino la ordenación que los integra, su conjunción o mutua adecuación. Lo estético de la experiencia es la estructuración de sus elementos. Es la coherencia que les

13 N. Carroll, Beyond Aesthetics, Cambridge and New York: Cambridge University Press, 2001, p. 5.

14 M. Beardsley, Aesthetics: Problems in the Philosophy of Criticism, Indianapolis: Hackett, 1981. También, «Aesthetic Experience Regained», The Journal of Aesthetics and Art Criticism, 28 (1969), pp. 3-11.

15 M. Beardsley, «Aesthetic Experience», en M. Wreen y D. Callen (eds.), op. cit, pp. 285-297. 
da continuidad, que lleva de unos a otros. Es la unidad interna por la que unos remiten a otros y se exigen mutuamente. Es la completud que los equilibra y armoniza entre ellos, que hace que los impulsos se contrapesen y las expectativas se resuelvan.

No entraremos en la consideración de tales características, que parecen pensadas para las obras clásicas, auráticas, recibidas en actitud de «recogimiento», y que si quisieran aplicarse al arte y experiencias de los últimos tiempos exigirían sin duda una revisión. Nos limitamos a subrayar que la definición de la experiencia estética en Beardsley parece presidida por la idea de atención desinteresada, absorta en la forma bella, y por la idea de que la experiencia se hace estética por la estructuración de sus componentes. Lo estético es ante todo contemplación y forma estructural. Por eso decíamos que la definición de Beardsley es «formalista».

B) Una segunda versión de la definición estética es la pragmática, representada por Richard Shusterman. La definición pragmática se presenta como alternativa a las definiciones tipo «envoltorio», la normalmente llamadas «esencialistas», cuyo efecto más notorio es hacer del arte un compartimento estanco, alejado de las otras practicas, aislado de la vida. Shusterman gusta de las afirmaciones contundentes y llamativas, como esas últimas, aunque en mi opinión carezcan en este caso de justificación argumental. Lo más relevante, bajo su punto de vista, es que la compartimentación del arte se evita al concebirlo como experiencia (acogiéndose a la inspiración de John Dewey), una experiencia más, conformada en conjunción con otras, todas integradas en la vida ordinaria. La experiencia estética es el fin interno y la justificación del arte. Los objetos artísticos, los productos materiales que llamamos obras de arte «carecen de valor artístico al separarse de su uso-valor (actual y potencial) en la experiencia estética. Sin un sujeto que los experimente están muertos y carecen de significado» ${ }^{16}$. Esta idea, generalizada en el pragmatismo, de que una obra de arte carece de significado si no es objeto de una experiencia estética, me parece notoriamente falsa. Creo que debería contraponérsele esta otra, bastante simple: la obra significa lo que la hace significar la construcción de sus signos; la inscripción de los signos la hace significativa aunque en un tiempo nadie la vea, escuche o lea; cuando se contempla o se lee, se entiende y experimenta, se experimenta el significado inscrito en la obra; se entiende la obra porque ella de por sí es significativa. Todo lo cual no obsta para que su significado se actualice en interpretaciones diversas.

Sin embargo, desde el supuesto de que la obra carece de valor y significado al margen de la experiencia, es lógico pensar que el arte se define por la expe-

16 R. Shusterman, Pragmatist Aesthetics. Living Beauty, Rethinking Art, Oxford and Cambridge: Blackwell, 1992, p. 47. 
riencia estética. Así lo hace Shusterman, aunque insistiendo en que la suya es una definición evaluativa más que lógica. «Si la experiencia estética constituye un fin y valor intrínsecos, entonces puede haber buenas razones para definir el arte en términos de ella, aunque muchas obras de arte no consigan producirla. Tal definición (de esencia más bien evaluativa que lógica) no pretende recubrir compartimentalmente todo lo conocido históricamente como arte, sino destacar lo que más importa en el arte, así como incrementar la apreciación de lo artístico, incluso si eso también supone reconocer el arte fuera de su dominio tradicionalmente establecido» ${ }^{17}$.

El problema empieza a partir de ahí. Beardsley para definir el arte por la experiencia necesitaba una caracterización fidedigna de la experiencia estética, y la buscó una y otra vez. Debía pensar que si el arte es aquello que provoca una experiencia estética, necesitamos saber qué es la experiencia estética para poder identificar el arte. Si no conocemos al arte en sí mismo, conozcámoslo por su efecto: sepamos cuál es y en qué consiste el efecto estético, sepamos reconocer las características de la experiencia estética. Shusterman, en cambio, no necesita caracterizar la experiencia estética. Tras algunas elucubraciones sobre las ventajas y dificultades de una posible definición, parece concluir que no se puede definir claramente la experiencia estética. Es más, tal definición sólo introduciría oscuridad, confusión. «La experiencia estética parece demasiado escurridiza como para tener mucho poder explicativo. Aunque es innegable que existe, no existe como algo que podamos claramente aislar y definir; de ahí que al definir el arte como experiencia estética, estamos definiendo lo comparativamente claro y concreto por medio de algo oscuramente elusivo e indefinible» ${ }^{18}$.

Ahora bien, si definimos el arte por la experiencia, y la experiencia resulta indefinible, ¿que es lo que hemos definido? Se diría que nada, que estamos sencillamente ante una definición que no define, que es una falsa definición. El propio Shusterman parece reconocerlo así: «si la experiencia estética es esencialmente indefinible, explicar el arte en términos de ella no nos llevará demasiado lejos. Lo que es peor, tal definición puede inspirar confusiones en la estética» ${ }^{19}$. Sin embargo, mantiene la definición estética. La mantiene, pues aunque carezca de capacidad explicativa, no sea de carácter lógico, parece tener otras ventajas. ¿Cuáles?

La primera es cierta aptitud para la evaluación. No es que sea un criterio de valor en sentido estricto, no es que podamos valorar objetivamente una obra por la experiencia que genera. Es algo más vago y quizás más sutil: «Las 
satisfacciones disfrutadas en la experiencia estética procuran una especie de demostración 'por latido inmediato' del valor del arte» ${ }^{20}$. Es decir, si a lo largo de la experiencia tengo el pálpito de que una obra es buena, es que es buena. ¿Para qué necesitamos ningún otro criterio de valor? La otra ventaja de la definición estética es la que le da carácter pragmático. Defina más o menos, la definición vale por sus repercusiones prácticas. Nos sitúa mejor en el campo de la experiencia ordinaria, frente a las cosas, frente a los demás; nos predispone favorablemente hacia lo estético. Hace que tengamos más experiencias estéticas, y hace que las experiencias sean mejores. Aunque cabe preguntar: ¿cómo sabemos que son mejores si carecemos de algún otro criterio de valor, más allá de la pulsión cardiaca?

La definición estética le sirve a Shusterman para liberar al arte de las definiciones esencialistas que lo encapsulan y apartan de la vida. Y le sirven, sobre todo, para ensanchar notablemente las líneas de demarcación de lo artístico, de modo que quede integrado el arte popular, la cultura de los mass-media. Nada que objetar por mi parte a ese último propósito. Lo que no veo claro es que el procedimiento teórico empleado (la levedad de la teoría) sea el más eficaz para lograrlo.

C) La tercera versión de definición estética a que habíamos aludido es la comunicativa. La propone Gary Iseminger, presentándola como un «nuevo esteticismo», una versión reformulada del «esteticismo tradicional» de Beardsley. Lo que aporta de nuevo es el énfasis en la comunicación estética como condición de lo artístico y criterio de valor. El esteticismo tradicional se desdobla en dos tesis, funcional y evaluativa, que tienen su respectivo correlato en el nuevo esteticismo.

Las tesis son, en el esteticismo tradicional:

Tesis funcional: «Algo es una obra de arte si y sólo si su función es la de proporcionar una experiencia estética».

Tesis evaluativa: «Una obra de arte es una buena obra si y sólo si tiene la capacidad de proporcionar una experiencia estética» ${ }^{21}$.

En el nuevo esteticismo:

Tesis funcional: «La función de la obra de arte y la práctica del arte es la de fomentar la comunicación estética».

Tesis evaluativa: «Una obra de arte es una buena obra de arte en la medida en que tiene capacidad de permitir la apreciación» ${ }^{22}$.

20 Ibid., p. 57.

21 G. Iseminger, The Aesthetic Function of Art, Ithaca ans London: Cornell University Press, 2004, pp. 8 y 9.

22 Ibid., p. 23. 
En lo que toca a la tesis funcional, el nuevo esteticismo evita cuidadosamente todo esencialismo, prescinde de cualesquiera condiciones necesarias y suficientes. No declara nada sobre lo que sea la obra de arte, sino sobre las prácticas aceptadas en la institución informal del mundo del arte. Dice cuál es la función que se espera de la obra artística, qué ejercicio ha de fomentar. Y ese no es otro que la comunicación estética. ¿Qué es lo propio de la comunicación estética?, ¿qué la hace ser estética? Una de las ventajas que el autor ve en su definición es que no necesita suponer ninguna actitud o atención especial cualificada como estética, no tiene que recurrir a conceptos como el de desinterés o de distanciamiento, que tantas críticas han sufrido a partir sobre todo de G. Dickie, no tiene que definir las características de la experiencia, como hace Beardsley. La comunicación estética tampoco consiste necesaria ni peculiarmente en la comprensión de cierto contenido semántico encarnado en la obra; lo inexcusable, lo que la determina como estética, es el papel central que en ella tiene la apreciación. La única condición necesaria de lo estético es «que el concepto de apreciación debe entrar en la caracterización de cualquier situación que haya de tener estatus estético de cualquier tipo» ${ }^{23}$. En efecto, la apreciación es la piedra de toque de la definición de Iseminger.

La apreciación no tiene por qué ser apreciación de lo artístico. Lo definitorio de la apreciación no es un concepto de arte ni alguna noción previa de lo estético. No es lo artístico ni lo estético lo que da sentido a la apreciación. Antes bien, es la apreciación la que determina el estatus estético. Al igual que la comunicación estética es la función que el mundo del arte asigna a la obra artística. Por lo demás, a la obra artística no se le exige ninguna cualidad interna. Y no se le exige porque lo definido no es propiamente la obra, sino la función que se espera de ella. Eso sí, aparte de que ciertos objetos artísticos estén diseñados y capacitados para la apreciación, cualquier cosa puede funcionar como obra de arte con tal de convertirse en objeto de apreciación.

«Apreciación es descubrir que experimentar una situación es algo valioso en si mismo» ${ }^{24}$. Apreciar es experimentar algo, y la experimentación es ante todo un conocimiento directo de cierta situación, acontecimiento, estado de hechos u objeto físico: un conocimiento anclado en lo sensorial, pero que no se limita a lo sensible. El concepto de experiencia, anota Iseminger, es epistémico. Lo que se descubre en la apreciación es que la experiencia es valiosa en sí misma. Se valora el objeto o situación porque se valora la experiencia que eso proporciona. Al valorar se pone el acento más en la experiencia derivada que en aquello que la provoca. Ahora bien, lo que me parece realmente significativo es la afirmación de Iseminger de que la apreciación se opone al mero 
gusto. Para valorar algo hace falta que uno piense que eso es bueno. Más aún, hace falta estar dispuesto a transmitir ese pensamiento y compartirlo con los demás, estar dispuesto a respaldar la opinión, explicar sus motivos, apoyarla con razones. La valoración genuina ha de ser comunicable. Por otro lado, como queda claro en la tesis evaluativa y se desprende de lo anterior, la apreciación se convierte también en el criterio de valor del arte: la obra más valiosa es la más capaz de fomentar la apreciación. Y cabría añadir, la que da más motivos para que la valoración sea comunicable.

A mi entender, un hueco del «nuevo esteticismo» es que no define el arte, pero de algún modo presupone una definición del arte. No define lo que es el arte, define la función del arte. Y al definir la función se compromete con las definiciones institucional e histórica (como reconoce el propio Iseminger). Más con la institucional, pues la función que atribuye a la obra artística es la que le viene asignada por un mundo del arte informalmente institucionalizado.

Además, no creo que sea muy convincente su identificación de lo estético. La valoración de una experiencia como efecto de cierto objeto no parece suficiente para que aparezca lo estético. Al no haber ninguna especificidad en la experiencia valorada, ni en el objeto que la promueve, cualquier experiencia podría ser estética. Lo que llevaría a la disolución total de lo estético. En contra, no basta con decir que la belleza es el «ejemplo principal» de lo estético; hay que articular lo estético en torno a la belleza. Llevaban razón los clásicos: lo estético consiste en la percepción placentera de lo sensible bello. Supone una mirada especial y un objeto bello. A partir de ahí se podrá prolongar o reformular el concepto de lo estético. Pero si se anulan las bases de partida será difícil llegar a una noción compartible, de la que todos podamos servirnos.

El gran desafío es intentar pensar una valoración estética comunicable que no sea reductible al gusto; al gusto, se supone, entendido como mero sentimiento placentero, privativo de cada uno, excluyente de cualquier análisis o pensamiento. La pregunta que dejo en el aire es si la exigencia de una valoración estética comunicable tendría o no que conectar con la vía iniciada por Hume de abrir el gusto a las cualidades de los objetos, reconociéndose influenciado por éstas. Más que negar el sentimiento placentero, ponerlo en relación con las cualidades de los objetos. Educar el gusto para dotarlo de esa delicadeza que permite discernir mejor dichas cualidades, y que el gusto quede moldeado en alguna medida por ellas. Así es cómo en verdad la valoración estética podrá ser comunicable. Pues, salvo que se adopte una posición trascendental, si no son las referidas al objeto, ¿qué otras razones podrían respaldar nuestro juicio de valor a la hora de comunicarlo? 


\section{EL ARTE ¿ES O NO CUESTIÓN DE GUSTO?}

Las definiciones estéticas en su mayoría pretenden abrir puertas por las que escapar del reduccionismo estético, al menos en el sentido fuerte en el que lo caracterizamos al principio como una reducción del arte a gusto, o sea, reducción del arte a belleza y de la belleza a gusto subjetivo. Puede dudarse de que generalmente lo consigan. En cualquier caso, hay un autor, crítico y teórico del arte, que no hace ascos a esa reducción. La asume y la legítima. Es Clement Greenberg.

El siguiente texto necesita poco comentario:

«Si todo y cualquier cosa se puede intuir estéticamente, entonces todo y cualquier cosa se puede intuir y experimentar artísticamente. Lo que coincidimos en llamar arte no puede ser separado definitiva o terminantemente de la experiencia estética en general. (Que esto haya empezado a verse sólo recientemente -gracias sobre todo a Marcel Duchamp- no le quita verdad). Sometida a la prueba de la experiencia, la noción de arte demuestra depender finalmente, no de la maestría en el oficio (como mantenían los antiguos), sino de un acto de distanciamiento sobre el que precisamente yo llamaba la atención. Al coincidir con la experiencia estética en general, el arte significa sencillamente, aunque no sea algo simple, un cambio de actitud respecto a tu propia conciencia y sus objetos.

De esta forma, resulta que existe algo como arte en sentido amplio (at large): un arte que cualquier persona realiza, o puede realizar, en cualquier lugar y en cualquier tiempo. En su mayor parte (para expresarlo débilmente), el arte en sentido amplio se realiza de modo impensado y solipsista, como un arte que no puede ser adecuadamente comunicado por la persona que lo realiza o lo 'crea'. La intuición estética de un paisaje, cuando no la transmites a través de un medium como el lenguaje, dibujo, música, danza, mimo, pintura, escultura o fotografía, te pertenece sólo a ti; pero el hecho de que no comuniques tu intuición a través de un medium viable no la priva de su 'estatus' de arte (Croce lo entrevió). La diferencia entre arte en sentido amplio y lo que el mundo hasta ahora coincidía en llamar arte es la que hay entre lo incomunicado y lo comunicado. Pero no creo que esta diferencia se sostenga» 25 .

Todas y cada una de las cosas se pueden intuir estéticamente; y lo que se puede intuir estéticamente, se puede intuir y experimentar artísticamente. ¿En qué consiste la intuición estética? Para Greenberg, la intuición estética es cualquier intuición, no transitiva, absorta en su objeto, que suspende todo interés práctico (o sea, «desinteresada» en sentido kantiano) y es necesariamente evaluativa. En otros términos, es una contemplación vinculada a la apreciación 
o evaluación, hasta el punto de que la evaluación es inevitable y concluyente: «La intuición estética es enteramente una cuestión de valor y valoración, nada mas que eso» ${ }^{26}$. Además, la intuición es el eje de toda experiencia estética.

En definitiva, cualquier cosa que se intuya o perciba estéticamente puede experimentarse como arte. Puesto que la intuición es el núcleo de la experiencia estética cabe concluir que para que un objeto sea arte basta con que se tenga una experiencia estética del mismo.

Entre todo lo que esto conlleva, destacaría dos puntos. El primero es que algo se convierte en arte por un simple proceso mental de cualquier persona. En palabras ya citadas, «al coincidir con la experiencia estética en general, el arte significa sencillamente, aunque no sea algo simple, un cambio de actitud respecto a tu propia conciencia y sus objetos». Basta una operación mental, que ni siquiera ha de ser reflexivamente consciente -un acto «impensado y solipsista»-, basta la intuición que alguien tiene por su cuenta, la intuición estética de algo, un paisaje u objeto, para que eso se transmute en obra de arte. $\mathrm{El}$ acto del que surge el arte tiene lugar en el interior de la mente; hace que algo sea artístico sin necesidad de plasmarse en un medio físico, y sin necesidad de comunicarlo a ninguna otra persona. No entiendo por qué Greenberg dice que Croce «entrevió» esto último. Hizo algo más que entreverlo, le dio un cuerpo teórico bastante sólido en su teoría de la expresión.

$\mathrm{El}$ arte puede ser fruto de una intuición estética privada y particular. De aquí deriva Greenberg la distinción de dos clases de arte, el arte en sentido amplio, genérico, que es el generado por la intuición estética, y el arte en sentido clásico. El primero es un arte no formalizado, no plasmado en un medium; pura intuición íntima, no comunicada. El otro es el tradicionalmente reconocido como arte, formalizado, encarnado en un medio físico, dispuesto para la comunicación. Pero el propio Greenberg devalúa la distinción, al matizar que la diferencia entre ambos tipos de arte es gradual, tenue e incierta, hasta el punto de no creer que «esta diferencia se sostenga».

El arte y lo estético se identifican. Lo curioso es el papel que asigna Greenberg a Duchamp en el reconocimiento de tal identidad: gracias a él y sus readymades hemos acabado descubriéndola. «Desde [los readymades de Duchamp] también ha quedado claro que todo lo que de algún modo puede experimentarse puede ser experimentado estéticamente; y que todo lo que puede ser experimentado estéticamente también puede ser experimentado como arte. En resumen, no es exacto que el arte y lo estético se superpongan, ambos coinciden ${ }^{27}$. La opinión comúnmente aceptada hace de Duchamp el primer

26 Ibid., p. 6.

27 Cl. Greenberg, «Counter-Avant-Garde», en: J. Masheck, Marcel Duchamp in Perspective, Englewood Cliffs: Prentice-Hall, 1975, p. 128. 
responsable de que el arte se separase de lo estético, tanto de la belleza como de la encarnación sensible del significado. El mismo confesó que había elegido los readymades al margen de cualquier consideración estética. Greenberg le da la vuelta a esto. Así, lo que hemos aprendido de Duchamp es que cualquier cosa, un simple readymade, pues de ser intuido estéticamente. Lo que no quiere decir sino que puede ser valorado, pues no se olvide que la intuición «es enteramente una cuestión de valor y valoración». Puede ser valorado positiva o negativamente; eso es lo de menos, lo único que cuenta es que se lo valora (al tiempo que se lo contempla intransitivamente), y en tanto tal es intuido estéticamente. Por lo mismo, se convierte en arte. Al mandar el urinario a la exposición Duchamp nos prestó un gran servicio teórico: nos hizo advertir que el arte es asimilable a la intuición estética, que todo puede ser arte desde el momento en que se lo contempla evaluativamente, que sobre cualquier cosa cabe hacer una valoración estética positiva o negativa, puede ser objeto de gusto o disgusto. Y el urinario efectivamente merece una valoración. Suponemos que negativa, en el caso de Greenberg.

Conectamos así con el segundo punto que queríamos destacar en el discurso de Greenberg: el gusto es el que valora, la valoración estética es manifestación del gusto. «La intuición de valor estético es un acto en el que a uno le gusta mas o menos algo o le disgusta mas o menos. Lo que gusta o no gusta es un afecto o un grupo de afectos. El valor estético o la calidad es un afecto» ${ }^{28}$. Volvemos a los clásicos: el juicio estético es un juicio de gusto. En particular, Greenberg reivindica a Kant, para quien el juicio estético lo que predica es un sentimiento del sujeto, el sentimiento de la vida, el placer. Aunque conviene recordar que el placer en Kant es el efecto del libre juego de imaginación y entendimiento, de la armonización de las facultades trascendentales. Para Greenberg, al margen de cualquier trascendentalismo, lo que expresa el gusto es un «afecto». En cualquier caso, algo que cae del lado de la emoción o el sentimiento, aunque no sea un sentimiento cualquiera, sino un sentimiento con capacidad evaluativa, desde el que se valora el objeto; pero algo recibido, no ejercido, inmune a la deliberación o el razonamiento, como se afirmaba en la cita que recogíamos al comienzo.

El valor estético se mide en términos de satisfacción o desagrado; o sea, es un fenómeno del gusto. Si el arte resulta de la percepción valorativa, y la valoración es un acto de gusto, la conclusión no puede ser otra: el arte es cuestión de gusto. «Cuando no hay un juicio de valor estético, un veredicto del gusto, entonces tampoco hay arte, no hay experiencia estética de ningún tipo. Es tan simple como esto» ${ }^{29}$. Lo que hace que el arte exista y funcione como

28 Homemade Esthetics, op. cit., p. 7.

29 Ibid., p. 62. 
tal es el gusto. «Cualquier cosa que entra en el contexto del arte queda sujeta, inexorablemente, a la jurisdicción del gusto $-\mathrm{y}$ al ordenamiento del gusto» ${ }^{30}$. Greenberg ofrece la versión teórica más descarnada de la reducción del arte a lo estético.

No hay aquí lugar para perfilar una alternativa al reduccionismo estético. Sólo sugerimos cuál debería ser, a nuestro entender, su punto de partida. Hay que pensar por separado lo artístico y lo estético; lograr que el concepto de lo uno y lo otro sean independientes, no reductibles entre sí. Pues lo estético es más amplio que lo artístico, abarca mucho más, el arte no debe ser determinante en la concepción de lo estético. A su vez, lo estético no es lo que hace que algo sea arte. El arte no es cuestión de gusto. Sin embargo, creo que el arte tiene una dimensión estética que hay que pensar. Aunque lo estético en el arte y lo estético fuera del arte no son la misma cosa. Los elementos estéticos del arte son subsidiarios, derivan de algo más originario, que acaso sea la naturaleza simbólica o cognitiva del arte. De ser así, lo estético del arte dependería del conocimiento, se insertaría en una relación cognitiva. O mejor, incluso lo estético comportaría una relación cognitiva.

Pero éstas no son sino meras sugerencias que, al no desarrollarlas, se desvanecen en el aire.

30 Cl. Greenberg, «Avant-Garde Attitudes: New Art in the Sixties», en: The Collected Essays and Criticism, Vol. 1, Chicago and London: The University of Chicago Press, 1986-1993, p. 293. 